\title{
Participants opinions related sports betting games in Turkey
}

\section{Türkiye'deki spor bahis oyunlarına ilişkin iştirakçi görüşleri}

\section{Can Çavin Ötkan ${ }^{1}$ Tekin Çolakoğlu ${ }^{2}$}

\section{Özet}

Bu araştırmada, 13 Şubat 2019 tarihinde sonuçlanan "İddaa İhalesi" neticesinde gerçekleşen değişimler çerçevesinde, Türkiye'de sanal ortam araciluğ ile yasal ve yasa dişı spor bahislerine iştirak eden bireylerin görüşlerinin incelenmesi amaçlanmaktadır. Bu bağlamda, nitel araştırma metotlarından durum çalışması deseni kullanılmış, amaçlı örneklem yöntemi ile belirlenmiş 14 iştirakçiden yarı yapılandırılmış görüşme formu ile veri toplanmış ve içerik analizine tabi tutulmuştur. Elde edilen bulgular neticesinde, katilımciların spor bahis oyunlarına maddi ve manevi motivasyon kaynakları doğrultusunda yöneldikleri tespit edilmiştir. Yasa dış1 bahis oyunları ile tanışma şekilleri incelendiğinde ise en yüksek frekansa sahip alt kategorinin "arkadaş aracillğı ile" ( $f=7$ ) olduğu görülmektedir. Yasa dişı spor bahsi şirketlerine para aktarım yöntemi olarak katılımcilar arasında en yaygin kullanilan yöntem "kripto para transferi” ( $\mathrm{f}=8$ ) olarak belirlenmiştir. Yasa dışı spor bahsi şirketlerini değerlendiren katılımcılar açısından olumlu yönlerin olumsuz yönlere oranla daha yoğun bir biçimde algilandığı görülmektedir. İştirakçilerin yasal spor bahis oyunlarından beklentileri ise maddi ve manevi olarak iki ayrı alt kategoride tasniflenmiştir. Araştırmadan elde edilen bulgular neticesinde,

\footnotetext{
${ }^{1}$ Research Assistant, Gazi University, Sport Sciences Faculty, Department of Sport Management, cancavin@gmail.com (iD) Orcid ID: 0000-0003-3800-4923

${ }^{2}$ Assoc. Prof. Dr., Gazi University, Sport Sciences Faculty, Department of Sport Management, tcolakoglu@gmail.com (iD) Orcid ID: 0000-0002-4250-6769
} 
who evaluate illegal sports betting companies, it is seen that positive aspects are perceived more intensely than negative aspects. It has been determined that the expectations of the participants from the legal sports betting services are divided into pecuniary and incorporeal. As a result, the participants in the survey, it was determined that not satisfied with the legal betting services in Turkey. It was demonstrated that this situation did not change after the "İddaa Tender" on 13 February 2019. For this reason, it has been determined that the sports betting participants prefer illegal betting companies.

Keywords: Sports betting games, legal sports betting, illegal sports betting.

(Extended English summary is at the end of this document)

\section{GİRİ̧̧}

Bahis, öne sürdüğü tahmini doğru sonuçlanacak kişinin, maddi yahut manevi ödül kazanmay1 hak etmesi hususunda yapılan anlaşma olarak ifade edilmektedir (Tüzüner, 2013: 246). Buna bağlı olarak spor bahis oyunları ise, bir veya birden fazla sportif müsabakanın neticesine yahut içerisinde cereyan edecek hadiselere yönelik tahminde bulunmak üzere kurgulanmış bir olgudur. İsabetli tahmini gerçekleştiren iştirakçiler, tanımlanmış kaideler doğrultusunda ikramiye kazanmaktadırlar. Spor bahislerinde oynayan ve oynatan olmak üzere iki taraf mevcuttur.

Sanayi devrimi, pek çok sosyolojik fenomeni etkilediği gibi boş zaman kavramının da gelişiminde önemli rol oynamıs, bunun neticesinde de sportif etkinlikler günlük yaşamın ötesine geçerek bir endüstri haline getirmiştir. Bu gelişmelere bağlı olarak spor, önemli bir tüketim kalemi ve büyük çapta finans hareketlerinin yaşandığı bir sektöre dönüşmüştür. Günümüzde televizyon ve internet, sporun küreselleşmesinin sağlanmasında ve kimliğinde önemli değişiklikler meydana getirmiş, spor bahis oyunlarının söz konusu kitle iletişim araçları ile rahatlıkla ulaşılabilir ve oynanabilir olmasını sağlamıştır. Bunun yanı sıra spor bahis oyunlanı; yüksek miktarlarda para kazanma ihtimali sayesinde bireylerin hayallerini gerçekleştirebilmeleri firsatını vermesi açısından oldukça cazip bir etkinlik olarak görülmektedir (Yaşar, 2010: 139).

Spor bahis oyunlarının bu denli cazip hale gelmesi neticesinde, zamanla devlet yönetimleri tarafından hukuki düzenlemeler ile sınırlandırma ihtiyacı ortaya çıkmış ancak bu durum da yasa dışı spor bahsi olarak yeni bir olgunun doğmasına neden olmuştur. Bu bağlamda, sanal ortamda yasal ve yasa dışı bahis oyunlarına iştirak eden bireylerin Türkiye'deki bilhassa 13 Şubat 2019 tarihinde sonuçlanan "İddaa İhalesi" neticesinde gerçekleşen değişimler çerçevesinde yasal ve yasa dışı spor bahis oyunlarına yönelik görüşlerinin incelenmesi araştırmanın amacını meydana getirmektedir. 


\section{KAVRAMSAL ÇERÇEVE}

\subsection{Spor Bahis Oyunlar1}

Spor; sınai bir nitelik kazanmasıyla birlikte, kendi süreci içinde maddi kaynaklar oluşturmayı sürdürmüş, bunun neticesinde de bahis ekonomisi, oldukça etkin bir kavram olarak ortaya çıkmıştır. Buna istinaden, spor bahis oyunlarının günümüzde ulaşmış olduğu mali hacimle, spor ekonomisinin oldukça önemli bir kısmını oluşturduğu görülmektedir (Kızar, Dalk1lıç ve Bayrak, 2015: 220).

Spor sektöründe böylesi etkin bir noktaya ulaşmış olan bahis oyunlarının, yasal kaideler çerçevesinde düzenlenmesi de gayet tabii bir durum olarak değerlendirilmektedir. Bu noktada, Türkiye'deki hukuki düzenlemeler neticesinde spor bahis oyunlarının yasal ve yasa dışı olmak üzere tasniflendiğini söylemek mümkündür.

\subsubsection{Yasal Bahis}

Türkiye'de kamu otoritesinden lisans almış, denetleyici ve yetki sahibi kurumların kontrolü altında oynatılan oyunlar "yasal bahis" olarak ifade edilebilmektedir. Söz konusu kamu otoriteleri, Spor Toto Teşkilat Başkanlı̆̆ı ve Türkiye Jokey Kulübü’dür (Çelik, 2017: 8).

7258 sayılı Futbol ve Diğer Spor Müsabakalarında Bahis ve Şans Oyunları Düzenlenmesi Hakkında Kanun (1959) kapsamında spor bahis oyunları, özel hukuk tüzel kişilerine devredilebilmekte yahut mal ve hizmet satın alınabilmektedir. Bu bağlamda, 2019 yllında gerçekleştirilen ihaleyi Demirören Holding ve Scientific Games'in oluşturduğu Şans Girişim kazanmıştır (Talimciler, 2019). Bu ihale sonrasında, yasal spor bahis oyunlarına yönelik ilginin artırılması amacı ile bahis seçeneklerinin artırıldığı ve canlı bahis uygulamasının getirildiği gözlemlenmektedir.

Diğer yandan, Spor Toto Teşkilat Başkanlığ1 tarafindan lisans almış, elektronik ortamda yasal olarak spor bahsi oynatma hizmeti veren 6 adet bayi bulunmaktadır. Bunlar şu şekildedir:

- Bilyoner

- Nesine

- Misli

- Oley

- Tuttur

- Birebin (Spor Toto Teşkilat Başkanlığı, 2019).

Yine 7258 sayll Kanun'un (1959) b ve d bendine göre; kamu otoritesi tarafindan yetkilendirilmiş, denetleyici lisansa sahip kurumlar olan bu elektronik bayilerin haricindeki ortamlarda, kanuna aykırı biçimde spor bahsi oynatan kişiler için 4 ila 6 yıl arası hapis cezası, oynayan kişiler için ise beş bin ila yirmi bin Türk Lirası arasında para cezası uygulanmaktadır.

\subsubsection{Yasa Dişı Bahis}

Sanal platformda yasa dişı spor bahis faaliyetleri ilk olarak 1990'lı yıllarda organize edilmeye başlamış, 2000'li yıllardan itibaren ise bu mecrada etkin olan kuruluşların gerek sayısında gerek işlem hacimlerinde büyük çapta artış meydana gelmiştir. Elektronik ortamda oynanan spor bahis oyunları günümüzde tüm dünyada spor bahis oyunları pastasının en büyük dilimi olarak karşımıza ç1kmaktadır (Claussen ve Miller, 2001: 350; European Comission, 2011: 3).

Türkiye'deki mevcut durum incelendiğinde ise, Mali Suçları Araştırma Kurulu Başkanlığı'nın yayınlamış olduğu en güncel Faaliyet Raporu'na göre, yasa dışı bahis oynayan ve oynatan şahıslara yönelik yapılan işlemlerde el konulan miktarlar şu şekildedir:

- 158.610.506 Türk Liras1,

- 1.962.955 Amerikan Dolar1,

- 8.731.169 Avro,

- 1.464 Sterlin, 
Ötkan, C. Ç., \& Çolakoğlu, T. (2020). Türkiye'deki spor bahis oyunlarına ilişkin iştirakçi görüşleri. Journal of Human Sciences, 17(1), 359-368. doi:10.14687/jhs.v17i1.5945

- 1.716 Altin (Gr),

- 2.788 Avustralya Dolar1,

- 1.000 Japon Yeni (Mali Suçları Araşturma Kurulu Başkanlı̆̆1, 2018: 43).

Diğer yandan, Türkiye'deki yasal spor bahis oyunlarının yıllık cirosu 11 milyar Türk Lirası olarak açıklanırken, yurt dışı merkezli şirketler aracılı̆̆ ile oynanan yasa dışı spor bahis oyunlarının yıllık cirosunun 42 milyar Türk Lirası seviyesine ulaştı̆̆1 görülmektedir. Ek olarak, yasal spor bahis oyunlarına 6.1 milyon, yasa dışı spor bahis oyunlarına ise 10 milyonun üzerinde kişinin iştirak ettiği ifade edilmektedir (Gülderen, 2019).

$\mathrm{Bu}$ verilerden yola çıkarak, yurtdışı merkezli yasa dışı bahis şirketlerinin son dönemde Türkiye pazarına yönelik faaliyetlerini artırdıkları, yasa dışı bahsin ulaşmış olduğu parasal hacmin yüksek seviyelere ulaştı̆ı ve kamu otoritesi dahlinde olmayan mecralarda oynanan elektronik altyapılı spor bahislerinin aynı zamanda kayıt dışı ekonominin artmasına sebebiyet verdiği görülmektedir.

\section{YÖNTEM}

Araştırmada, durum çalışması deseni kullanılmıştır. Nitel araştırma metotlarından durum çalışması deseni, bir ya da birkaç duruma ilişkin etkenlerin derin bir biçimde araştırılmasını ve bu etkenlerin mevcut durum ile olan etkileşiminin incelenmesini sağlamaktadır (Yıldırım ve Şimşek, 2006: 73). Araştırmanın çalışma grubunu amaçlı örnekleme yöntemi ile belirlenmiş, sanal ortamdaki yasa dışı spor bahislerine iştirak eden 14 katılımcı oluşturmaktadır. Verilerin toplanması aşamasında yarı yapılandırılmış soru formu aracıllğı ile görüşme tekniği kullanılmış, verilere içerik analizi uygulanmıştır.

\section{BULGULAR}

\subsection{Katılımcıların Demografik Bilgilerine İlişkin Bulgular}

Tablo 1. Katılimciların Demografik Bilgileri

\begin{tabular}{|c|c|c|c|c|}
\hline & Yaş & $\begin{array}{l}\text { Yasal Spor Bahsi } \\
\text { Oynama Süresi }\end{array}$ & $\begin{array}{c}\text { Yasa Diş1 Spor Bahsi } \\
\text { Oynama Süresi }\end{array}$ & $\begin{array}{c}\text { Alg1lanan Gelir } \\
\text { Durumu }\end{array}$ \\
\hline K1 & 20 & 6 & 3 & Düşük \\
\hline K2 & 21 & 4 & 3 & Düşük \\
\hline K3 & 21 & 5 & 4 & Düşük \\
\hline K4 & 29 & 14 & 3 & Orta \\
\hline K5 & 29 & 13 & 7 & Orta \\
\hline K6 & 30 & 12 & 9 & Orta \\
\hline K7 & 32 & 14 & 7 & Yüksek \\
\hline K8 & 36 & 14 & 6 & Orta \\
\hline K9 & 31 & 9 & 6 & Orta \\
\hline K10 & 25 & 5 & 3 & Düşük \\
\hline K11 & 40 & 21 & 9 & Yüksek \\
\hline K12 & 32 & 13 & 8 & Orta \\
\hline K13 & 27 & 9 & 5 & Orta \\
\hline K14 & 30 & 14 & 7 & Orta \\
\hline
\end{tabular}

Tablo 1'de katılımcıların demografik bilgileri verilmektedir. Buna göre, katılımcıların yaşlarının 20-40 aralığında, yasal spor bahsi oynama süresilerinin 4-21 yıl aralığında ve yasa dışı spor bahsi oynama sürelerinin 3-9 yll aralığında olduğu görülmektedir. Algilanan gelir durumu değişkeni incelendiğinde ise, 4 katılımcının düşük, 8 katılımcının orta ve 2 katılımcının ise yüksek gelir seviyesi algısına sahip oldukları tespit edilmiştir. 
Ötkan, C. Ç., \& Çolakoğlu, T. (2020). Türkiye'deki spor bahis oyunlarına ilişkin iştirakçi görüşleri. Journal of Human Sciences, 17(1), 359-368. doi:10.14687/jhs.v17i1.5945

\subsection{Katılımcıların Spor Bahis Oyunlarına Yönelik Motivasyon Kaynaklarına İlişkin Bulgular}

Tablo 2. Katılımcıların Spor Bahis Oyunlarına Yönelik Motivasyon Kaynakları

\begin{tabular}{|c|c|c|c|}
\hline Kategori & $\begin{array}{c}\text { Alt } \\
\text { Kategoriler }\end{array}$ & Kodlar & f \\
\hline \multirow{5}{*}{$\begin{array}{l}\text { Katılımciların Spor Bahislerine } \\
\text { Yönelik Motivasyon Kaynakları }\end{array}$} & \multirow{2}{*}{$\begin{array}{c}\text { Maddi } \\
\text { Motivasyon } \\
\text { Kaynaklar1 }\end{array}$} & Geçim kaynağ1 olarak görme & 2 \\
\hline & & $\begin{array}{c}\text { Bütçeye katkıda bulunacak miktarda } \\
\text { kazanma }\end{array}$ & 7 \\
\hline & \multirow{3}{*}{$\begin{array}{c}\text { Manevi } \\
\text { Motivasyon } \\
\text { Kaynaklar1 }\end{array}$} & Heyecan & 12 \\
\hline & & Müsabaka seyir zevkini artırma & 7 \\
\hline & & Tatmin hissi & 3 \\
\hline
\end{tabular}

K3: "Spor bahislerini, izlediğim macı daha keyifli hale getirsin diye oynuyorum. Bir de yaptrğım tahminin

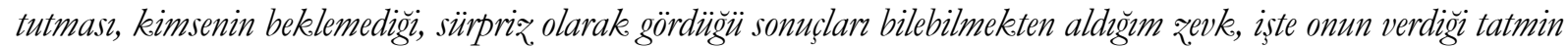
bissini seviyorum. Para kazanmak gibi bir amacım yok, kaldn ki zaten çok düsü̈k miktarlarda para ayrryorum".

K6: "Öncelikli motivasyon kaynağm tabi para kazanmak. Kazanyorum da aslanda. Bu tip sirketlerin internet sayfalarnda yullhk bilançonuఇu görebiliyorsunuz, istatistiklerinizi veriyor yani. Mesela geçen 1 yul içerisinde ber ay ortalama 2000-2500 TL arasi kar etmisim. Ama bu isten ciddi paralar kazanmak istiyorsan öyle 5 TL basayım 5000 TL alayım olmuyor, büyü̈k meblağlar riske etmek gerekiyor. Ömrümden ömür gidiyor maçlar izlerken tabi o aym".

\subsection{Katılımcıların Yasa Dışı Spor Bahis Oyunlarıyla Tanışma Şekillerine İlişkin Bulgular}

Tablo 3. Katılımcıların Yasa Dışı Spor Bahis Oyunlarıyla Tanışma Şekilleri

\begin{tabular}{ccc}
\hline Kategori & Alt Kategoriler & f \\
\hline \multirow{3}{*}{ Katılımcıların Yasa Dışı Spor } & Arkadaş Aracılı̆̆ıla & 7 \\
\cline { 2 - 3 } Bahisleriyle Tanışma Şekilleri & İnternet Reklamları & 5 \\
\cline { 2 - 3 } & Stadyum Reklam Panosu & 1 \\
\cline { 2 - 3 } & Futbol Takımı Forma Sponsoru & 1 \\
\hline
\end{tabular}

K5: 'İngiltere Premier Ligi'ni u₹un zamander düzenli olarak takip ederim. Takımlarn çoğunun formalarnda babis şirketlerinin reklamlarm görünce ilgimi çekti ve merak ettim açleşası. Sonrasinda ufak bir araștırmayla önde gelen bahis sirkettlerinden birine üye olup, para yatımp kolaylhkla babis oynamaya bașladim ve kazandiğm miktarlar da sıkentısız, cekebildim. Bu nedenle bir süre sonra bunun yasa diš olduğunu öğrendiğimde çok

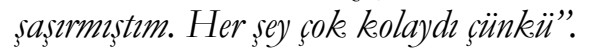

\subsection{Katılımcıların Yasa Dışı Spor Bahis Şirketlerine Para Transferinde Kullandıkları} Yöntemlere İlişkin Bulgular

Tablo 4. Katılımcıların Yasa Dışı Spor Bahis Şirketlerine Para Transferinde Kullandıkları Yöntemler

\begin{tabular}{ccc}
\hline Kategori & Alt Kategoriler & f \\
\hline Katılımcıların Yasa Dışı Spor & Banka Havalesi & 7 \\
\cline { 2 - 3 } Bahis Şirketlerine Para & Cep Havale & 5 \\
\cline { 2 - 3 } Transferinde Kullandıkları & Kredi Kartı & 2 \\
\cline { 2 - 3 } Yöntemler & Kripto Para Transferi & 8 \\
\hline
\end{tabular}

K4: "Para aktarmmnda önceden banka havalesi ve cep havale kullanyyordum. Sirketlerin Türkiye'de paravan besaplar oluyor, oraya banka havalesi yapuyorsun, şirket onu senin babis hesabına aktaryor kolayca. Ancak son 
Ötkan, C. Ç., \& Çolakoğlu, T. (2020). Türkiye'deki spor bahis oyunlarına ilişkin iştirakçi görüşleri. Journal of Human Sciences, 17(1), 359-368. doi:10.14687/jhs.v17i1.5945

zamanlarda bu tip paravan hesaplar tespit edildiği için sıkıntr yașanmaya bașlandı. Cep havaleye de aylhk. $1500 \mathrm{TL}$ işlem limiti getirdiler o da biraz kullanısssz, hale geldi. Ancak bitcoin, litecoin gibi kripto paralarm takibi çok zor yapuliyor. O nedenle artık bu yöntemi kullanyorum, henüz, hiçbir sorun yaşamadım”.

\subsection{Katılımcıların Yasa Dışı Spor Bahsi Şirketleri Hakkındaki Değerlendirmelerine İlişkin Bulgular}

Tablo 5. Katılımcıların Yasa Dışı Spor Bahsi Şirketleri Hakkındaki Değerlendirmeleri

\begin{tabular}{|c|c|c|c|}
\hline Kategori & Alt Kategoriler & Kodlar & $\mathrm{f}$ \\
\hline \multirow{6}{*}{$\begin{array}{l}\text { Katılımcıların Yasa } \\
\text { Dışı Spor Bahsi } \\
\text { Şirketleri Hakkındaki } \\
\text { Değerlendirmeleri }\end{array}$} & \multirow[t]{4}{*}{ Olumlu yönler } & Yüksek Oranlar & 14 \\
\hline & & Branş Çeşitliliği & 14 \\
\hline & & Bahis Çeşitliliği & 14 \\
\hline & & Bonus Firsatları & 4 \\
\hline & \multirow[t]{2}{*}{ Olumsuz Yönler } & Web Sitelerine Erişim & 2 \\
\hline & & İkramiye Tahsilatı & 3 \\
\hline
\end{tabular}

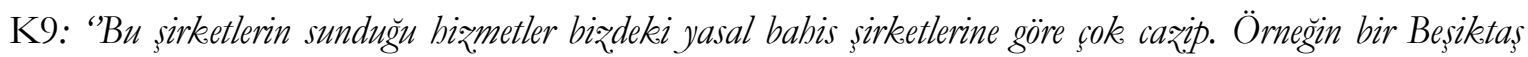
kazanır babsine bizde 1.15 oran verilirken yasa dıș sirketlerde bu oranlar 1.60'lardan basslyor. Yani düsünsenize, 1000 TL'ye 1600 TL kazanmak varken neden gidip 1150 TL kazanmayn kabul edeyim ki? Biraz enayi yerine konuyoruz diye dïs̆̈̈nüyorum".

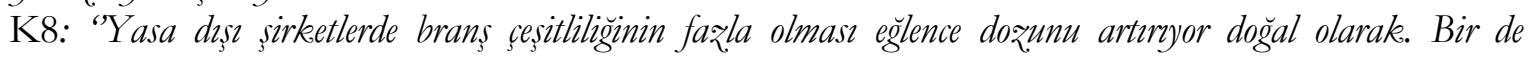
Türkiye'de yaym olmayan müsabakalar o sitelerden canl iəleyebiliyorsunu₹. Ben örneğin bir gün babis sitelerinden birinde dolaşırken canl bir dart maç yaymma denk geldim. Cok hoşuma gitti, ilgimi çekti. Şimdi üzerine bahis oynamasam bile aşıp i₹liyorum dart maçlarn, hatta kendim de oynamaya başladim. Öyle bir faydası oldu bana".

K12: "Yasa diș babis sitelerine erişim açısindan mesela biliyorsunuz bu internet siteleri belli araliklarla engelleniyor ama dakikasinda sitenin uzantıs değistiviliyor ve tekrar bizmete açliyor. Yine bir selkilde erisebiliyorsunuz ama sürekli yeni uฉantiy ögrenebilmek için internette arastırma yapmak, bu sürecte gerçek site ile sabte olanlar birbirinden ayırt etmeye çalısmak bir süre sonra insanı sikezyor".

K9: "Kazamlan ikramiyeyi çekmek güvenilir belli bașl șirketlerde sorun olmuyor. Orada yașanan tek sorun süre açısından baz̧en bir hafta on günü buluyor olması. Biz̨deki yasal bahis şirketleri en fazla 24 saat içinde paran besabma yatmr. Ancak bu yurtdlşındaki güvenilir șirketlerin haricindeki kü̈ülk babis sirketlerinde amiyane tabirle paranın üstüne çökme durumlar olabiliyor. Cü̈nkü adam biliyor ki sen Türkiye'den yapıyorsun bu işi. Zaten illegal bir durumdasin. Kimi kime şikâyet edeceksin”.

\subsection{Katılımcıların Yasal Spor Bahsi Hizmetlerinden Beklentilerine İlişkin Bulgular}

Tablo 6. Katılımciların Yasal Spor Bahsi Hizmetlerinden Beklentileri

\begin{tabular}{|c|c|c|c|}
\hline Kategori & Alt Kategoriler & Kodlar & f \\
\hline \multirow{4}{*}{$\begin{array}{c}\text { Katilimcilarin Yasal } \\
\text { Spor Bahsi } \\
\text { Hizmetlerinden } \\
\text { Beklentileri }\end{array}$} & Maddi Beklentiler & $\begin{array}{l}\text { İkramiye bedellerinin } \\
\text { yükseltilmesi }\end{array}$ & 12 \\
\hline & \multirow{3}{*}{ Manevi Beklentiler } & $\begin{array}{c}\text { Bahis çeşitliliğinin } \\
\text { artır1lmas } 1\end{array}$ & 14 \\
\hline & & $\begin{array}{c}\text { Branş ve lig } \\
\text { seçeneklerinin } \\
\text { artırılması }\end{array}$ & 14 \\
\hline & & $\begin{array}{l}\text { Canlı bahis } \\
\text { uygulamasının } \\
\text { genişletilmesi }\end{array}$ & 14 \\
\hline
\end{tabular}


Ötkan, C. Ç., \& Çolakoğlu, T. (2020). Türkiye'deki spor bahis oyunlarına ilişkin iştirakçi görüşleri. Journal of Human Sciences, 17(1), 359-368. doi:10.14687/jhs.v17i1.5945

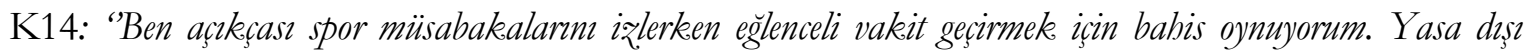
babis sirketteri de bana bunu sağlyyor. Babis ve brans çesittiliği ile canli bahis olaylar çok daha genis yelpazede bizdeki İddaa oynnlarna göre. Bu tip babisler sayesinde maçlar iə̨lemek daba keyifli hale geliyor doğal olarak. Yasal babis oyunlarnnda bunlar ya bic yok ya da sinurh sekilde var. Bu ynl canl bahis geldi İddaa'ya ama ne kadar yeterli tartısılir. Bu şekilde devam ettiüi sürece yasal babis hizmetlerini tercih etmem için bir sebep yok"."

K11: "Beni yasa dişı bahis oynamaya iten tamamen maddi getirisi oldu. Benim yasal bahis hizmetlerinden tek beklentim oranlarn yurtdşsındaki seviyeye getirilmesi. Ben ister miyim yasa diş işlere bulaşayım, kaynt disı ekonomiyi arturan bir olusumda bulunarak devletime zarar vereyim. Ama devletin de șapkayn önüne koyup bir düş̈̈nmesi lazım. Bunca insan neden bu yasa diş șirketleri tercib ediyor, ben ne yapabilirim bu konuda diye. Bu son ibale sonrası biraz ümitliydik ancak geldiğimiz noktada sağlanan bizmetler bala oldukesa yetersiz".

K9: "Yasal bahis hizmetlerinden beklentim, dünyanm önde gelen spor bahis şirketlerinde sunulan imkanlarn tamaminn bize sağlanması. Aksi halde sadece ben değil, kimsenin yasa diş babis şirketlerinden vazgegeceğini sanmiyorum. Ortada bir de tuhaf bir durum var. Bu yasa diş șirketlerin internet sitelerine uzantı değissse de erişim sürekli açı, devlet bunu bir türlü engelleyemiyor. Oynayanlarn bir kısmm tespit ettiler, yasa gereği 5000 TL ceza verdiler. Bu ceza da şabsen beni caydrmaktan uzak bir meblăg ashnda. Yani devlet bunu gerçekten engellemek istese çoktan bir yolunu bulmustu diye düsïnüyorum. Ilginc geliyor bana bu durum".

\section{TARTIŞMA}

Kattlımcıların spor bahis oyunlarına yönelik motivasyon kaynaklarının maddi motivasyon kaynakları alt kategorisi altında; geçim kaynağı olarak görme ve bütçeye katkıda bulunacak miktarda kazanma, manevi motivasyon kaynakları alt kategorisi altında ise heyecan, müsabaka seyir zevkini artırma ve tatmin hissi olarak tasniflendiği görülmektedir.

Fang ve Mowen (2009: 126), sanal ortamda spor bahis oyunlarına iştirak eden bireyler üzerinde yapmış oldukları araştırmada katılımcıların bahis oynamadaki motivasyon kaynaklarının para kazanmak, sosyal etkileşim, heyecan, özsaygı kazanma ve kaçış olarak tespit etmişlerdir.

Lee, Chung ve Bernard (2014: 852), spor bahsi oynayan bireylerin davranışlarına yönelik gerçekleştirmiş oldukları çalışmalarında, iştirakçilerin motivasyon kaynaklarının heyecan yaşama, stres atma, başarı hazzı, para kazanma ve tutku olarak 5 ayrı kategori altında toplandığı bulgulamıslardır.

Erdoğan (2008: 33) ise çalışmasında, bireylerin zengin olma hayallerini gerçekleştirme yolunda bahis oyunlarını önemli bir aracı olarak gördüklerini belirtmektedir. Bu nedenle, bahis oynamadaki ana motivasyonu para kazanmak olan katılımcıların, ikramiye bedelleri daha yüksek olan yasa dışı şirketlere yönelmeleri olağan bir durum olarak yorumlanabilmektedir.

Katılımcıların yasa dışı spor bahis oyunlarıyla tanışma şekilleri incelendiğinde; arkadaş aracıllğılla, internet reklamları, stadyum reklam panosu ve futbol takımı forma sponsoru olarak 4 farklı alt kategorinin tespit edildiği görülmektedir. Yasa dışı spor bahis şirketlerine para aktarımında ise katılımcıların banka havalesi, cep havale, kredi kartı ve kripto para transferleri yöntemlerini kullandıkları belirlenmiştir. Gerek yasa dışı spor bahis oyunlarıyla tanışma şekli, gerek söz konusu şirketlere para aktarımında kullanılan yöntemler incelendiğinde internet olgusunun önemli bir etken olarak karşımıza çıktığı görülmektedir.

Çelik'in (2017: 73) spor bahsi oynayan bireylere yönelik yapmış olduğu araştırmasında elde ettiği bulguların da bu durumu destekler nitelikte olduğu düşünülmektedir. Çelik; internet kullanımı yaygın olan genç bir nüfusa sahip olunmasının, yasa dışı şirketlere erişim ve para transferindeki engelleme ve yaptırımların caydırıcı nitelikte olmamasının neticesinde yasa dışı spor bahislerine olan ilginin giderek arttı̆̆ını belirtmiştir.

Katllımcılar, yasa dışı spor bahsi şirketleri hakkındaki değerlendirmelerinde olumlu ve olumsuz yönlerin mevcudiyetinden bahsetmişlerdir. Buna göre; yüksek oranlar, branş çeşitliliği bahis çeşitliliği ve bonus firsatları olumlu yönler olarak nitelendirilirken, web sitelerine erişim ve ikramiye tahsilatı olumsuz yönler olarak ifade edilmiştir.

Araştırmaya dahil olan katılımciların yasal spor bahsi hizmetlerinden beklentileri incelendiğinde ise bunların maddi ve manevi beklentiler olarak 2 ayrı alt kategoriye ayrıldığı görülmektedir. 
İkramiye bedellerinin yükseltilmesi maddi beklenti olarak karşımıza çıkmakta, bahis çeşitliliğinin artırılması, branş ve lig seçeneklerinin artırılması ve canlı bahis uygulamasının genişletilmesi ise manevi beklentiler olarak değerlendirilmektedir.

Altınışık (2017: 244) da yasadışı bahis oyunlarının kayıt dışı ekonomiye olan etkisini incelediği çalışmasında, bireylerin yasadışı bahislere yönelmesindeki ana faktörleri; bahis, branş ve lig çeşitliliği sayısının fazla olması şeklinde sıralamıştır.

Ötkan ve Çolakoğlu (2019) ise, yasal ve yasa dışı bahis oyunlarına iştirak eden bireylerin 13 Şubat 2019 "İddaa İhalesi" öncesindeki görüşlerini incelemiş ve yasal spor bahsi hizmetlerine yönelik olan beklentiye ilişkin benzer bulgular elde etmişlerdir. Bu durum da bize, söz konusu ihale sonrası İddaa oyunlarında gerçekleşen değişimlerin, iştirakçilerin beklentilerini karşılamadığını göstermektedir.

Buna ek olarak Deloitte'in, Türkiye'de sanal ortamda yasa dışı bahis oynayanlar üzerinde yapmış olduğu araştırmada ortaya çıkan sonuçlar incelendiğinde; katılımcıların \%51’i yasa dışı bahsi tercih etmekte ve yasa dışı bahis oynayanların \%80’i sanal ortamı tercih etmektedir. Yasa dışı bahis oynayanların \%62'si sunulan hizmetlerin daha cazip olduğunu belirtmiş ancak \%60'1 yasa dışı bir eylemde bulunduklarını bilmediklerini ifade etmiştir (Deloitte Türkiye, 2015).

\section{SONUÇ VE ÖNERİLER}

7258 sayılı Kanun kapsamında gerçekleştirilen İddaa oyununa yönelik ihale neticesinde tek bir girişimin oyunları düzenleme yetkisine sahip olabildiği görülmektedir. Ancak bu durumun yasal bir zeminde oluşacak rekabet ortamına engel olduğu, buna istinaden de iştirakçilerin talep ettiği hizmet kalitesinin sağlanamadığı söylenebilir. Diğer yandan, iştirakçilerin yasa dışı bahis oyunlarına katılımını engellemek amacıyla uygulanan yaptırımların caydırıcılıktan uzak bir seviyede olduğu, bu durumun da ülke ekonomisine ciddi boyutlarda zarar verdiği gözlemlenmektedir.

Yasal bahis hizmetlerini iştirakçiler adına cazip hale getirecek aksiyonların yetkili merciiler tarafından alınmasının, araştırmada ortaya konulan problemlerin çözümüne ilişkin etkili bir yöntem olarak önerilmektedir. Bu bağlamda, ilgili yasal düzenlemelerle birlikte yurt içi ve yurt dışı merkezli spor bahis şirketlerinin Türkiye'deki pazara dahil edilmesinin rekabeti sağlayacağ1 ve hizmet kalitesini artıracağı düşünülmektedir. Bu sayede iştirakçilerin yasa dışı faaliyetlere yönelim düzeylerinin ve buna bağlı olarak yasa dışı spor bahsinden kaynaklanan kayıt dışı ekonomi hacminin düşeceği öngörülmektedir.

Sonuç olarak, araştırmaya katılan iştirakçilerin, 13 Şubat 2019 tarihinde yapılan "İddaa İhalesi" sonrası gerçekleşen değişimlere rağmen Türkiye'de verilen yasal bahis hizmetlerinden memnun olmadıkları, taleplerin karşılanamadığı ve bu nedenle de yurt dışı merkezli, sanal ortamda hizmet veren yasa dışı bahis şirketlerine yöneldikleri tespit edilmiştir.

\section{KAYNAKLAR}

Alınışık, İ. (2017). Kayıt dışı ekonomi: İllegal bahis. Selçuk Üniversitesi Sosyal ve Teknike Araşstımalar Dergisi, $13,239-248$.

Claussen, C. L., \& Miller, L. K. (2001). The gambling industry and sports gambling: A stake in the game? Journal of Sport Management, 15(4), 350-363. https://doi.org/10.1123/jsm.15.4.350

Çelik, M. A. (2017). Spor babisi oynayan bireylerin babis oynama güdülerinin belirlenmesi. Yüksek Lisans Tezi, Gazi Üniversitesi Sağlık Bilimleri Enstitüsü, Ankara.

Deloitte Türkiye. (2015, Aralı 8). Türkiye spor bahsi pazar. Deloitte Touche Tohmatsu Limited. https://tinyurl.com/rrvwuk7

Erdoğan, İ. (2008). Futbol ve futbolu inceleme üzerine. İletişim kuram ve araștrma dergisi, 26(2), 1-58.

European Comission (2011, Mart 24), Green paper on online gambling in the internal market. European Comission, DG Internal Market and Services. https://tinyurl.com/sdcwzpe 
Ötkan, C. Ç., \& Çolakoğlu, T. (2020). Türkiye'deki spor bahis oyunlarına ilişkin iştirakçi görüşleri. Journal of Human Sciences, 17(1), 359-368. doi:10.14687/jhs.v17i1.5945

Fang, X., \& Mowen, J. C. (2009). Examining the trait and functional motive antecedents of four gambling activities: Slot machines, skilled card games, sports betting, and promotional games. Journal of Consumer Marketing, 26(2), 121-131. https://doi.org/10.1108/07363760910940483

Futbol ve Diğer Spor Müsabakalarında Bahis ve Şans Oyunları Düzenlenmesi Hakkında Kanun, (1959). T.C. Resmî Gazete, 10201, 9 Mayis 1959.

Gülderen, M. (2019, Mayıs 24). Kara bahis kurbanları. Posta. https://bit.ly/2G7wbcf

Kızar, O., Dalkılıç, M., \& Bayrak, M. (2015). Futboldaki şike olayları hakkında spor adamları ve spor yazarlarının düşüncelerinin incelenmesi. Akademik Sosyal Araştrrmalar Dergisi, 3(10), 212-222. http://dx.doi.org/10.16992/ASOS.502

Lee, C. K., Chung, N., \& Bernhard, B. J. (2014). Examining the structural relationships among gambling motivation, passion, and consequences of internet sports betting. Journal of Gambling Studies, 30(4), 845-858. https://doi.org/10.1007/s10899-013-9400-y

Mali Suçları Araştırma Kurulu Başkanlığ1 (2018, Eylül 5). 2018 Faaliyet Raporu. T.C. Hazine ve Maliye Bakanlığı, Mali Suçları Araştırma Kurulu Başkanlığı. https://bit.ly/38oyAvf

Ötkan, C. Ç., \& Çolakoğlu, T. (2019). "İştirakçilerin Türkiye'deki yasal ve yasa dışı spor bahislerine ilişkin görüşleri”, 2. Uluslararası Rekreasyon ve Spor Yönetimi Kongresi, 11-14 Nisan 2019, REKÇAD, 207, Muğla.

Spor Toto Teşkilat Başkanlığı. (2019, Nisan 18). Elektronik Bayiler. https://bit.ly/2TS6STV

Talimciler, A. (2019, Ocak 15). İddaa ihalesi ve futbol. Futbol Ekonomisi \& Endüstriyel Futbol. https://bit.ly/38qb3tX

Tüzüner, Ö. (2013). Kumar ve bahis borcu hakkında De Lege Ferenda düşünceler. Türkizye Barolar Birlïgi Dergisi, (107), 245-272.

Yaşar, M. R. (2010). Şans oyunları ve İddaa. Elektronik Sosyal Bilimler Dergisi, 9(34), 138-171.

Yıldırım, A., \& Şimşek, H. (2006). Sosyal bilimlerde nitel araştırma yöntemleri. (10. Baskı). Ankara: Seçkin.

\section{Extended English Summary}

\section{Introduction}

Betting is expressed as an agreement on whether the person whose prediction is correct will deserve to win a material or moral reward (Tüzüner, 2013: 246). Accordingly, sports betting games are the prediction of the result of one or more sports competitions or how they will develop. Participants who make the correct prediction earn prizes in line with the rules. There are two stakeholders; bettor and bet organizer in sports betting.

The fact that betting games reached such an effective point in the sports sector made it necessary to regulate them with legal rules. At this point, sports betting with legal regulations in Turkey are divided into legal and illegal. Legal betting in Turkey could be played by organizations licensed by the public authorities. The remaining platforms are considered as illegal bets (Çelik, 2017: 8).

\section{Purpose}

Purpose of the research; culminating in the February 13, 2019 "Idddaa Tender" with the following changes took place in Turkey, legal and illegal betting in virtual platform is to examine the opinions of the individuals participating in the game.

\section{Method}

Case study pattern, one of the qualitative research methods, was used in the study. The study group of the research consists of 14 participants who participated in illegal sports betting in the virtual platform, determined by the purposive sampling method. During the data collection phase, interview technique was used through the semi-structured questionnaire and content analysis was applied to the obtained data. 


\section{Results and Discussion}

It is seen that the age of the participants is in the range of 20-40, the duration of legal sports betting is in the range of 4-21 years, and the duration of illegal sports betting is in the range of 3-9 years. When the perceived income status variable was analyzed, it was found that 4 participants had low perception, 8 participants had medium and 2 participants had high income perception.

The motivation sources of the participants for sports betting are divided into two sub-categories, pecuniary and incorporeal. Pecuniary motivation sources; deem as a source of livelihood and earning enough to contribute to the budget, incorporeal motivation sources are excitement, increasing the pleasure of sports competition and feeling satisfied.

Fang and Mowen (2009: 126), in their research on individuals participating in sports betting games in the virtual platform, determined that the motivation sources of the participants in betting were earning money, social interaction, excitement, self-esteem and escape.

Lee, Chung and Bernard (2014: 852) found that the motivation sources of the participants were gathered under 5 different categories as excitement, stress relief, success pleasure, money making and passion in their studies on the behavior of individuals who place a sports betting.

The way participants informed of illegal sports betting games is as follows: through friends, online ads, stadium billboard and football team sponsor. In transferring money to illegal sports betting companies, it was determined that the participants used the methods of bank transfer, mobile money transfer, credit card and crypto money transfers.

When we examine the way of meeting illegal sports betting games and the methods used to transfer money to the companies in question, it is seen that the internet phenomenon is an important factor. It is thought that the findings obtained by Çelik (2017: 73) in his research on sports betting individuals also support this situation. Çelik stated that the interest in illegal sports betting has increased gradually as a result of the fact that there is a young population with a widespread use of the internet, access to illegal companies and the inhibition and sanctions of money transfer is not a deterrent.

Participants described the high betting odds, sports branch variety, betting variety and bonus opportunities in illegal sports betting companies as positive aspects, while accessing websites and cash proceeds were negative aspects. Altınış1k (2017: 244) stated that illegal betting was preferred because of the large variety of bets in his study, which examined the effect of illegal betting games on the informal economy.

It has been determined that the expectations of the participants from the legal sports betting services are divided into pecuniary and incorporeal. Increasing the prize worth is in the pecuniary expectation category, increasing the variety of bets, increasing the sports branch and league options and expanding the live betting application are in the incorporeal expectation category.

\section{Conclusion}

The tender for the İddaa held under the Law No. 7258 gives the authority to organize the games to a single business enterprise. However, it can be said that this situation obstructs the competitive environment and accordingly, the quality of service requested by the participants cannot be achieved. On the other hand, it is observed that the sanctions applied to prevent participation in illegal betting games are at a level that is not deterrent, and this situation causes serious damage to the national economy.

Taking the actions that will make the legal betting services attractive on behalf of the sports betting participants by the competent authorities is suggested as an effective proceeding for the solution of the problems posed in the research. In this context, for the creation of a competitive environment and increase the quality of services, the relevant legal regulations with domestic and foreign-based sports betting company is proposed to be included in the market in Turkey. In this way, it is foreseen that the level of inclination of the participants towards illegal activities and, accordingly, the unrecorded economy volume stemming from the illegal sports betting will decrease.

As a result, the participants in the survey, it was determined that not satisfied with the legal betting services in Turkey. It was demonstrated that this situation did not change after the "İddaa Tender" on 13 February 2019. For this reason, it has been determined that the sports betting participants prefer illegal betting companies. 